\title{
Right Heart Thrombus and Pulmonary Embolism in Patients with Life-Threatening Bleeding: Management of a Complex Condition
}

\author{
Enrico Bentivegna ${ }^{1}$ (D) Michelangelo Luciani ${ }^{1}$ • Valerio Spuntarelli ${ }^{1}$. Giorgio Sesti ${ }^{1}$ • Flavia Del Porto ${ }^{1,2}$. \\ Paolo Martelletti ${ }^{1,2}$
}

Accepted: 20 January 2021 / Published online: 8 February 2021

(C) The Author(s) 2021

\begin{abstract}
Right heart thrombus (RHT) in transit is an uncommon condition associated with high mortality. Increased use of echocardiography has allowed an easier detection of RHT; however, there is no consensus about the most appropriate management of this critical situation. Therapeutic strategy should be decided according to patient's haemodynamic parameters, clinical data, and bleeding risk. This paper, referring to the most current evidences, underlines the difficulty to establish the best therapeutic strategies in RHT among complex patients as there are no relevant guidelines. In some conditions, multidisciplinary management is the best way to find the most correct therapy despite the bad prognosis.
\end{abstract}

Keywords Right heart thrombus $\cdot$ Pulmonary embolism $\cdot$ Aortic dissection $\cdot$ Intracranial haemorrhage $\cdot$ Echocardiography

\section{Introduction}

Right heart thrombus (RHT) in transit is an uncommon situation, often concomitant with pulmonary embolism (PE), and associated with high mortality [1]. Increased use of echocardiography has allowed an easier detection of RHT; however, the optimal management of this condition remains controversial [2-5]. Herein, presenting a case of 82-year-old Caucasian man with subarachnoid bleeding, floating thrombus in right atrium, massive pulmonary embolism and Stanford B aortic dissection, we analyse the possible management of a difficult condition between thrombosis and bleeding risk. A multidisciplinary discussion was performed, and the most reasonable and less invasive way to treat patient was low molecular weight heparin as anticoagulant dose. This commentary,

This article is part of the Topical Collection on Medicine

Enrico Bentivegna

enrico.bentivegna@uniroma1.it

1 Internal Medicine Unit, Sapienza University of Rome-Sant'Andrea University Hospital, Via di Grottarossa, 1035-1039,

00189 Rome, Italy

2 Department of Clinical and Molecular Medicine, Sapienza University, Rome, Italy referring to the most current evidence and guidelines, underlines the difficulty to establish the best therapeutic strategies in RHT among complex patients as there are no relevant guidelines. In some conditions, multidisciplinary management is the best way to find the most correct therapy despite the bad prognosis.

\section{Complex Case Analysis}

An 82-year-old Caucasian man with Parkinson disease and dementia admitted to hospital emergency room after accidental fall with head injury. On the first presentation, vital signs were normal; brain computer tomography (CT) scans without contrast was performed showing small parafalcal subarachnoid bleeding (Fig. 1). Neurosurgical consultancy excluded surgical urgency, aspirin administration was suspended and prophylactic anticoagulant therapy with subcutaneous low molecular weight heparin was initiated. After few days of hospitalization, transthoracic echocardiography showed floating thrombus in right atrium (Clips 1 and 2). Blood analysis revealed normal blood count, electrolytes and creatinine levels $(0.71 \mathrm{mg} / \mathrm{dl}$, normal value $0.6-1.1 \mathrm{mg} / \mathrm{dl})$, high D-dimer level (4710 ng/ml, normal value $<243 \mathrm{ng} / \mathrm{ml}$ ) and normal levels of high-sensitive troponin T $(24.30 \mathrm{pg} / \mathrm{ml}$, normal value $<34.20$ $\mathrm{pg} / \mathrm{ml}$ ). Urgent thoracic CT with iodinated contrast showed 


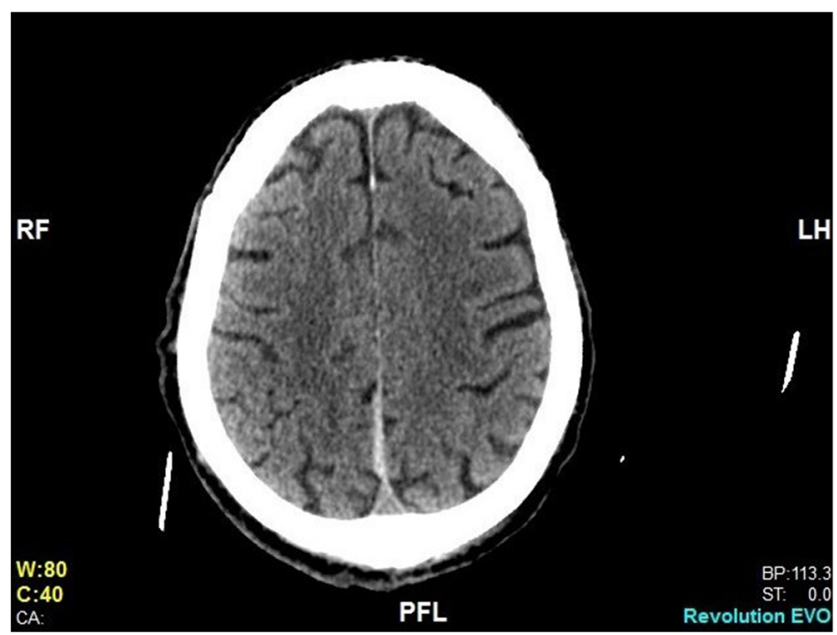

Fig. 1 Brain computer tomography (CT) scans without contrast was performed showing small parafalcal subarachnoid bleeding

massive pulmonary embolism (Fig. 2) and Stanford B aortic dissection (Fig. 3). A multidisciplinary case discussion was performed with the participation of internists, cardiologists, vascular surgeon and interventional radiologists. Due to the serious and complex clinical conditions, any type of emergency surgery such as surgical embolectomy was excluded. Fibrinolytic therapy was not an option as patient had aortic dissection and recent intracranial haemorrhage. Given the difficult management of continuous monitoring of partial thromboplastin time in a low-intensity ward, the use of intravenous heparin as an anticoagulant was avoided. The most reasonable and least invasive way to treat the patient was to increase the dose of low molecular weight heparin from 4000 international units (IU) every $24 \mathrm{~h}$ to 4000 IU every $12 \mathrm{~h}$. Unfortunately,

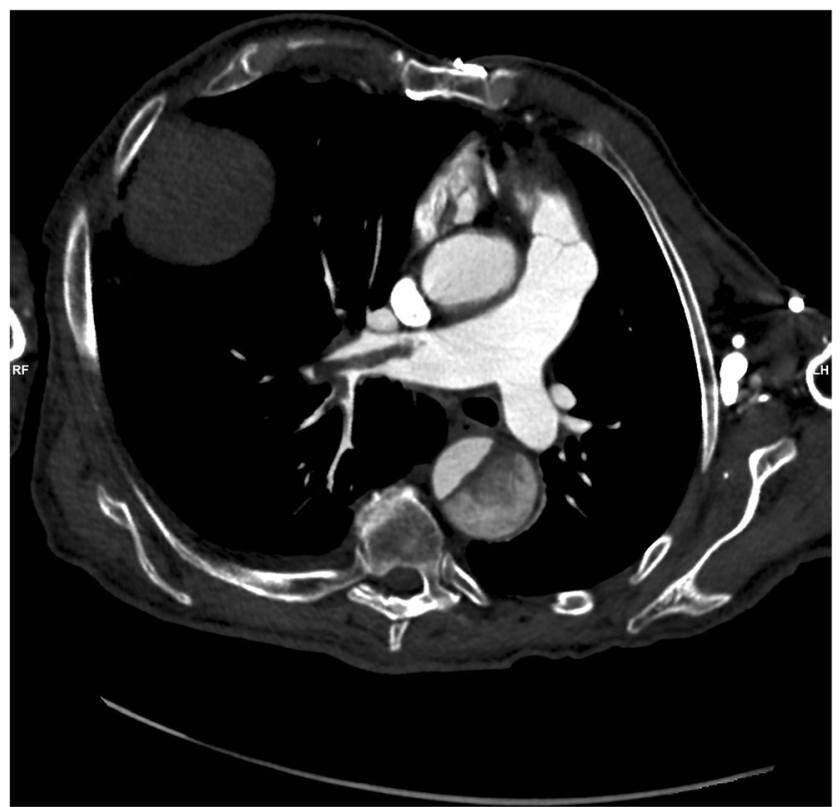

Fig. 2 Urgent thoracic CT with iodinated contrast showing massive pulmonary embolism

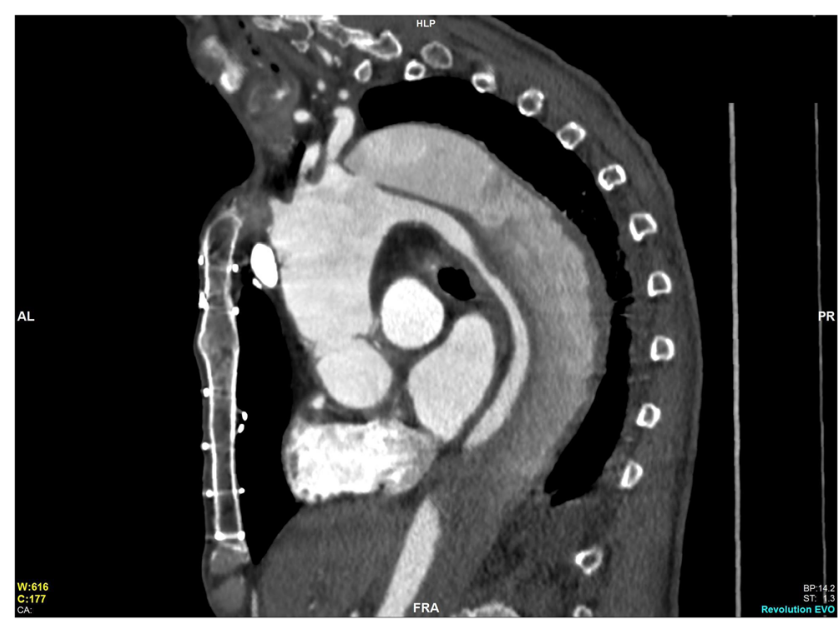

Fig. 3 Urgent thoracic CT with iodinated contrast showing Stanford B aortic dissection

the patient developed respiratory insufficiency and cardiogenic shock and passed 5 days later.

\section{Discussion and Perspectives}

The simultaneous presence of RHT and PE is recognized as a crucial emergency [1], and the mortality rate is higher compared to that of $\mathrm{PE}$ alone. Echocardiographic studies in $\mathrm{PE}$ patients show that the incidence of RHT is 7 to $18 \%$ [6]. RHT mortality is about $28 \%$, raising up to almost $100 \%$ in untreated patients [1]. Though some authors consider floating RHT as an in-transit pulmonary embolism, there is no consensus about the most appropriate management of this critical situation [2-5]. Therapeutic strategy should be decided according to patient's haemodynamic parameters, clinical data and bleeding risk [5]. Treatment options include anticoagulation, thrombolysis, percutaneous retrieval technique or surgical embolectomy. The latter one is primarily used in haemodynamically unstable patients [6]. Although thrombolysis shows better outcomes than anticoagulation, it is also associated with several absolute contraindications, first of all intracranial haemorrhage-like in the case of our patient $[7,8]$.

In this commentary, referring to the most current evidence and guidelines, we analyse a possible complex condition where it is not easy to find the correct therapeutic strategy. We highlight the difficulty to establish the best therapeutic strategies in the right heart thrombus among complex patients in the lack of relevant guidelines. In some conditions, multidisciplinary management is the best way to find the most appropriate therapy despite the poor prognosis.

We certify that the submission is original work and is not under review at any other publication. 
Supplementary Information The online version contains supplementary material available at https://doi.org/10.1007/s42399-021-00776-9.

Code Availability Not applicable.

Authors' Contribution All authors materially participated in the research. Dr. Bentivegna participated in data collection, article preparation and echocardiographic images acquisition.

All authors have approved the final article.

Funding Open Access funding provided by Università degli Studi di Roma La Sapienza.

Data Availability Not applicable.

\section{Declarations}

Ethics Approval and Consent to Participate Not applicable.

Consent for Publication Written informed consent was obtained by relatives of the patients for publication of this case report and accompanying images.

Competing Interests The authors declare no competing interests.

Open Access This article is licensed under a Creative Commons Attribution 4.0 International License, which permits use, sharing, adaptation, distribution and reproduction in any medium or format, as long as you give appropriate credit to the original author(s) and the source, provide a link to the Creative Commons licence, and indicate if changes were made. The images or other third party material in this article are included in the article's Creative Commons licence, unless indicated otherwise in a credit line to the material. If material is not included in the article's Creative Commons licence and your intended use is not permitted by statutory regulation or exceeds the permitted use, you will need to obtain permission directly from the copyright holder. To view a copy of this licence, visit http://creativecommons.org/licenses/by/4.0/.

\section{References}

1. Rose PS, Punjabi NM, Pearse DB. Treatment of right heart thromboemboli. Chest. 2002;121(3):806-14. https://doi.org/10. 1378/chest.121.3.806.
2. Charif F, Mansour MJ, Hamdan R, Najjar C, Nassar P, Issa M, et al. Free-floating right heart thrombus with acute massive pulmonary embolism: a case report and review of the literature. J Cardiovasc Echogr. 2018;28(2):146-9. https://doi.org/10.4103/jcecho.jcecho_ 6417.

3. Nkoke C, Faucher O, Camus L, Flork L. Free floating right heart thrombus associated with acute pulmonary embolism: an unsettled therapeutic difficulty. Case Rep Cardiol. 2015;2015:364780-4. https://doi.org/10.1155/2015/364780.

4. Ferrari E, Benhamou M, Berthier F, Baudouy M. Mobile thrombi of the right heart in pulmonary embolism: delayed disappearance after thrombolytic treatment. Chest. 2005;127(3):1051-3. https://doi.org/ 10.1378/chest.127.3.1051.

5. Konstantinides SV, Meyer G, Becattini C, et al. 2019 ESC Guidelines for the diagnosis and management of acute pulmonary embolism developed in collaboration with the European Respiratory Society (ERS): the Task Force for the diagnosis and management of acute pulmonary embolism of the European Society of Cardiology (ESC). Eur Respir J. 2019;54(3):1901647. https://doi.org/10.1183/ 13993003.01647-2019.

6. Chartier L, Béra J, Delomez M, et al. Free-floating thrombi in the right heart: diagnosis, management, and prognostic indexes in 38 consecutive patients. Circulation. 1999;99(21):2779-83. https://doi. org/10.1161/01.cir.99.21.2779.

7. Kearon C, Akl EA, Comerota AJ, Prandoni P, Bounameaux H, Goldhaber SZ, et al. Antithrombotic therapy for VTE disease: antithrombotic therapy and prevention of thrombosis, 9th ed: American College of Chest Physicians Evidence-Based Clinical Practice Guidelines [published correction appears in Chest. 2012 Dec;142(6):1698-1704]. Chest. 2012;141(2 Suppl):e419S-96S. https://doi.org/10.1378/chest.11-2301.

8. Vedantham S, Piazza G, Sista AK, Goldenberg NA. Guidance for the use of thrombolytic therapy for the treatment of venous thromboembolism. J Thromb Thrombolysis. 2016;41(1):68-80. https://doi.org/ 10.1007/s11239-015-1318-z.

Publisher's Note Springer Nature remains neutral with regard to jurisdictional claims in published maps and institutional affiliations.

Guarantor Prof. Martelletti Paolo, MD.

Publisher's NotePublisher's Note Springer Nature remains neutral with regard to jurisdictional claims in published maps and institutional affiliations. 